\title{
Sexual dimorphism of the craniofacial region in a South Indian population
}

\author{
Hema Nidugala ${ }^{1}$, BAMS, MSc, Chandana Bhargavi ${ }^{2}$, MBBS, MD, Ramakrishna Avadhani ${ }^{1}$, MBBS, MS,
} Bhagya Bhaskar ${ }^{1}$, MSc, PhD

INTRODUCTION To the best of our knowledge, the sexually dimorphic characteristics of the craniofacial region among the South Indian population are not available in the current literature. We aimed to determine these characteristics using discriminant function analysis.

METHODS A total of 80 recent skulls (40 male, 40 female) from the Department of Anatomy, Yenepoya Medical College, Yenepoya University, Karnataka, India, were analysed. Ten craniofacial parameters were measured and subjected to univariate and multivariate statistical analyses using the Statistical Package for the Social Sciences version 13.0.

RESULTS Statistical analyses revealed that the differences in the bizygomatic, orbital and biorbital breadths of males and females were significant $(p<0.05)$. Direct method gave an accuracy of $68.8 \%$ for sex determination. In stepwise analysis, bizygomatic breadth and upper facial height were selected, giving a $65.0 \%$ accuracy for sex prediction.

CONCLUSION Craniofacial parameters are sexually dimorphic. The present study established several features of craniofacial morphometry that can be used for sex determination among the South Indian population. The findings of the present study serve as a foundation for future studies that aim to compare craniofacial parameters among various ethnic groups in South India.

Keywords: craniofacial region, discriminant function analysis, metric parameters, sexual dimorphism, South Indian population

\section{INTRODUCTION}

Biological sex determination is a basic assessment in the evaluation of human remains. Further evaluation of the skeletal profile includes the identification of age at death, race, stature and ancestry. It is a challenge for forensic scientists and anthropologists to establish the biological profile of skeletal remains. Skeletal components are widely used in sex distinction because the skeleton is made up of hard tissues that can withstand extreme conditions and sex differences in the skeletal components exist due to differing growth spurts, growth patterns, strength of muscular attachments to the bone, ${ }^{(1)}$ and the presence of bony ridges and processes ${ }^{(2)}$ between the two sexes. Osteological variations between the sexes are population-specific. ${ }^{(3)}$ The phenotypic differences between the sexes are influenced by genetic and environmental factors. Changes in socioeconomic status, nutrition and physical activities also contribute to sexual dimorphism. ${ }^{(1)}$

Studies on sexing skeletons using osteometric measurements have been reported. ${ }^{(4,5)}$ The metrical method has been widely employed in the determination of sex. It involves subjecting the measurements of a set of parameters to various analyses. Discriminant function analysis, however, is a statistical method that explores the differences between groups by determining which combination of variables can best predict sex. In this method, the measurements of the different parameters are taken as independent variables, whereas sex is set as a dependent variable. Moreover, this method uses discriminant function equations that are population specific, thus making it the best method for sex determination.

The pelvis is considered to be the best skeletal structure for sexing, followed by parts of the skull such as the cranium, ${ }^{(6,7)}$ mandible, ${ }^{(5,8)}$ glabella, ${ }^{(9)}$ mastoid process ${ }^{(10,11)}$ and occipital bone. ${ }^{(12,13)}$ Craniofacial anthropometry for sex identification has been widely studied in various populations. The best parameter of craniofacial anthropometry reported for sex determination is bizygomatic breadth; other parameters include nasal width, head length, head width, ramus height, depth of face, upper facial height, and inner and outer canthal distance. ${ }^{(4,14-17)}$

As South India is composed of a heterogeneous population rich in ethnic and cultural diversity, and craniofacial growth is influenced by racial, ethnic, sexual and dietary differences, ${ }^{(15)}$ standard data of the local population is fundamental in the evaluation and diagnosis of craniofacial abnormalities. In other words, population-specific data is, desirable. In this regard, we conducted the present study to evaluate the degree of sexual dimorphism in a contemporary South Indian population. This data, to the best of our knowledge, is currently not available in the literature. Univariate and multivariate statistical analysis were used and discriminant functions were developed for the ten craniofacial parameters that were used in sex determination.

\footnotetext{
${ }^{1}$ Department of Anatomy, Yenepoya Medical College, Yenepoya University, ${ }^{2}$ Department of Anatomy, Kasturba Medical College, Manipal University, Mangalore, India Correspondence: Dr Bhagya Bhaskar, Lecturer, Department of Anatomy, Yenepoya Medical College, Yenepoya University, Deralakatte, University Road, Mangalore 575018, India. bagyabs@gmail.com
} 


\section{METHODS}

A total of 80 skulls (40 male, 40 female; age range 3560 years) from the Department of Anatomy, Yenepoya Medical College, Yenepoya University, South India, were used. Only skulls in good condition and with recorded sex identification were included. Skulls that were damaged, incomplete or without sex identification were excluded. Ten measurements were recorded for each cranium, using digital vernier callipers (Table I, Figs. 1 \& 2). Collected data were analysed using the Statistical Package for the Social Sciences version 13.0 (SPSS Inc, Chicago, IL, USA). Descriptive statistics, including mean and standard deviation (SD), were

Table I. Craniofacial parameters measured.

\begin{tabular}{ll}
\hline Craniofacial parameter & Description \\
\hline Bizygomatic breadth & The straight distance between the two zygia, which are the most laterally placed points on the zygomatic bone. \\
Facial length & The straight distance between the basion and the prosthion. \\
Upper facial height & The straight distance between the nasion and the prosthion. \\
Orbital breadth & The straight distance between the dacryon and the ectoconchion. \\
Orbital height & The maximum height from the upper to lower orbital borders, perpendicular to the dacryon-ectoconchion \\
& line (orbital breadth). \\
Biorbital breadth & The straight distance between two ectoconchion. \\
Interorbital breadth & The straight distance between the two dacrya. \\
Nasal height & The straight distance between the nasion and the nasospinale. \\
Nasal bone length & The distance between the nasion and the rhinion. \\
Nasal breadth & The maximum width between nasal borders of piriform aperture.
\end{tabular}
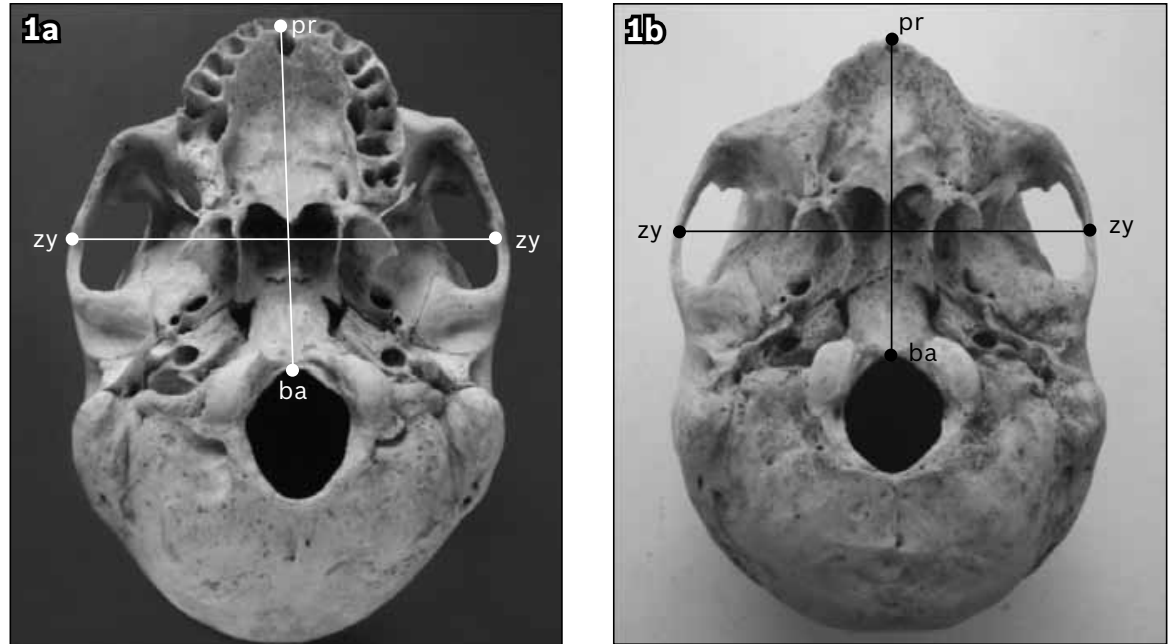

Fig. 1 Photographs of the basal view of (a) male and (b) female crania show points of craniofacial measurements. ba: basion; pr: prosthion; zy: zygion
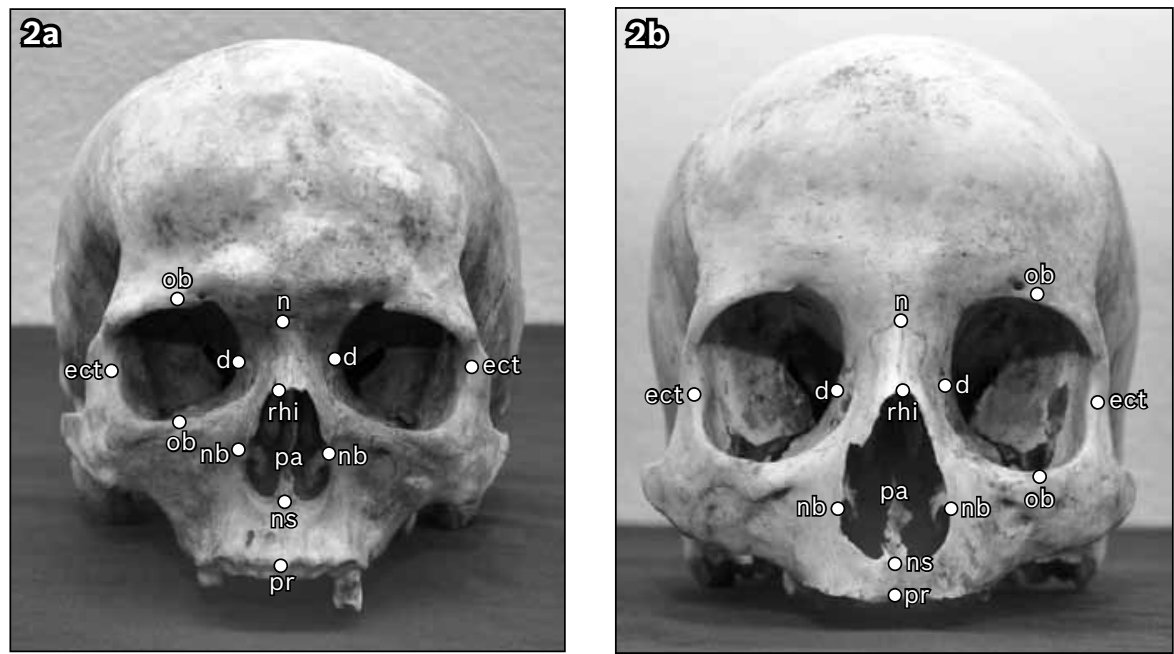

Fig. 2 Photographs of the frontal view of (a) male and (b) female crania show points of craniofacial measurements. d: dacryon; ect: ectoconchion; n: nasion; nb: nasal border; ns: nasospinale; ob: orbital border; pa: piriform aperture; pr: prosthion; rhi: rhinion 
Table II. Descriptive statistics of the craniofacial parameters measured $(n=80)$.

\begin{tabular}{|c|c|c|c|c|}
\hline \multirow[t]{2}{*}{ Craniofacial parameter } & \multicolumn{2}{|c|}{ Mean \pm SD } & \multirow[t]{2}{*}{$t$-value } & \multirow[t]{2}{*}{ p-value } \\
\hline & Male $(n=40)$ & Female $(n=40)$ & & \\
\hline Bizygomatic breadth & $118.41 \pm 5.30$ & $113.72 \pm 6.39$ & 3.57 & $0.001^{*}$ \\
\hline Facial length & $93.40 \pm 5.64$ & $92.50 \pm 5.89$ & 0.70 & 0.486 \\
\hline Upper facial height & $62.26 \pm 3.99$ & $63.33 \pm 5.16$ & 1.04 & 0.301 \\
\hline Orbital breadth & $40.21 \pm 2.09$ & $39.23 \pm 2.08$ & 2.09 & $0.040^{*}$ \\
\hline Orbital height & $32.94 \pm 1.96$ & $33.27 \pm 2.09$ & 0.72 & 0.472 \\
\hline Biorbital breadth & $96.61 \pm 3.56$ & $94.52 \pm 3.94$ & 2.49 & $0.015^{*}$ \\
\hline Interorbital breadth & $24.56 \pm 2.41$ & $24.55 \pm 2.34$ & 0.02 & 0.985 \\
\hline Nasal height & $47.87 \pm 2.94$ & $47.54 \pm 3.03$ & 0.50 & 0.618 \\
\hline Nasal bone length & $18.75 \pm 3.55$ & $19.99 \pm 2.90$ & 1.70 & 0.092 \\
\hline Nasal breadth & $24.29 \pm 1.87$ & $23.76 \pm 1.80$ & 1.32 & 0.192 \\
\hline
\end{tabular}

Note: All measurements are in $\mathrm{mm}$. * Difference between male and female is statistically significant.

obtained for each measurement. Stepwise, univariate and multivariate direct discriminant function analyses were performed to calculate specific discriminant function formulae for all parameters. A p-value of $<0.05$ was considered statistically significant.

\section{RESULTS}

Descriptive statistics (i.e. mean $\pm \mathrm{SD}, t$-value and $\mathrm{p}$-value) obtained for the ten craniofacial measurements are shown in Table II. All parameters were found to be larger in males, except for upper facial height, orbital height and nasal bone length. The p-values indicated that bizygomatic, orbital and biorbital breadths contributed significantly to sexual dimorphism $(\mathrm{p}<0.05)$.

Table III shows the results of the multivariate analysis using all craniofacial parameters. Direct method indicated that the accuracy of sex determination using all parameters is $68.8 \%$. Bizygomatic breadth had the highest structure matrix in relation to the discriminant function score. The formula derived is: $\mathrm{y}=(0.129 \times \mathrm{BZB})+(-0.023 \times \mathrm{FL})+(-0.089 \times \mathrm{UFH})+$ $(-0.109 \times \mathrm{OB})+(-0.137 \times \mathrm{OH})+(0.146 \times \mathrm{BOB})+(-0.140 \times \mathrm{IOB})+$ $(0.087 \times \mathrm{NH})+(-0.115 \times \mathrm{NBL})+(0.115 \times \mathrm{NB})+(-13.58)$, where BZB: bizygomatic breadth; FL: facial length; UFH: upper facial height; OB: orbital breadth; $\mathrm{OH}$ : orbital height; BOB: biorbital breadth; IOB: interorbital breadth; $\mathrm{NH}$ : nasal height; and NB: nasal breadth.

Using stepwise discriminant function analysis, only two variables - bizygomatic breadth and upper facial height were selected as the best discriminants between the sexes (Table III), with a Wilks' lambda value of 0.802 . Discriminant function was subsequently developed and a sectioning point calculated. Multivariate and cross-validation classification using the 'leave-one-out' classification method was conducted for all equations. Using stepwise discriminant score, an average accuracy of $65.0 \%$ was obtained (Table III). The formula derived is: $y=(0.178 \times B Z B)+(-0.135 \times U F H)+(-12.15)$.

The resulting average accuracy of sex prediction ranged from $58.8 \%$ to $68.8 \%$. In males, the single best parameter was the bizygomatic breadth $(62.5 \%)$, while the most significant dimensions in females were the bizygomatic breadth (75.0\%) and upper facial height (72.5\%). Other than that observed in the direct method, there was almost no difference between the original and cross-validated percentage average accuracies (Table IV).

\section{DISCUSSION}

Human anthropometry is influenced by factors such as geographical location, race, sex, age, dietary habits and occupation. ${ }^{(15)}$ Anthropometric studies can be used as an important tool for understanding biological variability. Craniofacial anthropometry plays a significant role in sex prediction, evolutionary biology, forensic investigation, ${ }^{(18)}$ craniofacial surgery and syndromology. ${ }^{(19)}$ The baseline values of local populations are fundamental in the evaluation and diagnosis of craniofacial abnormalities. It is important to have the standard data of indigenous ethnic groups in the evaluation of congenital malformations and facial defects. ${ }^{(15)}$

In the present study, except for upper facial height, orbital height and nasal bone length, all other parameters used showed larger values in males than in females. This finding is in agreement with other studies on craniofacial parameters. ${ }^{(4,5)}$ The difference in the craniofacial parameters may be due to the differential growth rates of males and females; females reach skeletal maturity at an earlier age and fusion of the facial sutures is delayed in males. These genetic processes are controlled by hormones, resulting in dimorphic characteristics. ${ }^{(1)}$ The present study shows that bizygomatic breadth and upper facial height are good discriminants of sex, with bizygomatic breadth being the best discriminant. Our finding concurs with other studies that found bizygomatic breadth to be the best parameter for sex determination in different populations. ${ }^{(4,14-17)}$ Males have broader bizygomatic breadth than females, possibly due to hypertrophy of the masseter and temporalis muscles in males, ${ }^{(4,20)}$ which causes greater convexity, and hence, increased breadth of the zygomatic arches. 
Table III. Discriminant function analysis for craniofacial parameters.

\begin{tabular}{|c|c|c|c|c|c|c|c|}
\hline $\begin{array}{l}\text { Craniofacial } \\
\text { parameter }\end{array}$ & $\begin{array}{l}\text { Unstandardised } \\
\text { coefficients }\end{array}$ & $\begin{array}{c}\text { Standardised } \\
\text { coefficients }\end{array}$ & $\begin{array}{l}\text { Wilk's } \\
\text { lambda }\end{array}$ & $\begin{array}{c}\text { Structure } \\
\text { matrix }\end{array}$ & Constant & Centroid & $\begin{array}{l}\text { Average } \\
\text { accuracy }\end{array}$ \\
\hline Direct method & & & 0.745 & & -13.582 & $\begin{aligned} M & =0.578 \\
F & =-0.578\end{aligned}$ & $68.80 \%$ \\
\hline BZB & 0.129 & 0.757 & & 0.691 & & & \\
\hline $\mathrm{FL}$ & -0.023 & -0.133 & & 0.136 & & & \\
\hline UFH & -0.089 & -0.410 & & -0.202 & & & \\
\hline $\mathrm{OB}$ & -0.109 & -0.227 & & 0.404 & & & \\
\hline $\mathrm{OH}$ & -0.137 & -0.278 & & -0.140 & & & \\
\hline BOB & 0.146 & 0.548 & & 0.482 & & & \\
\hline $\mathrm{IOB}$ & -0.140 & -0.332 & & 0.004 & & & \\
\hline $\mathrm{NH}$ & 0.087 & 0.259 & & 0.097 & & & \\
\hline NBL & -0.115 & -0.374 & & -0.330 & & & \\
\hline NB & 0.115 & 0.211 & & 0.255 & & & \\
\hline Stepwise method & & & 0.802 & & & $\begin{aligned} M & =0.490 \\
F & =-0.490\end{aligned}$ & $65.0 \%$ \\
\hline BZB & 0.178 & 1.046 & & 0.813 & -12.146 & & \\
\hline UFH & -0.135 & -0.626 & & -0.237 & & & \\
\hline
\end{tabular}

BOB: biorbital breadth ; BZB: bizygomatic breadth; F: female; FL: facial length; IOB: interorbital breadth; M: male; NB: nasal breadth; NBL: nasal bone length; $\mathrm{NH}$ : nasal height; OB: orbital breadth; $\mathrm{OH}$ : orbital height; UFH: upper facial height

Table IV. Validity of functions on independent samples.

\begin{tabular}{lcc}
\hline Method & $\begin{array}{c}\text { Original } \\
\text { accuracy }\end{array}$ & $\begin{array}{c}\text { Cross } \\
\text { validation (IS) }\end{array}$ \\
\hline Direct & 68.8 & 62.5 \\
Stepwise & 65.0 & 63.8 \\
Bizygomatic breadth & 68.8 & 67.5 \\
Upper facial height & 58.8 & 60.0 \\
\hline
\end{tabular}

Data is expressed as percentage. IS: independent sample

Using the cranial measurements of white South Africans, an overall accuracy of $85.7 \%{ }^{(16)}$ for sex prediction was reported, whereas cranial measurements of 8 black South Africans yielded an average accuracy of $77 \%-80 \% .^{(21)}$ In the same population, Dayal et al used 14 cranial and 6 mandibular measurements and reported a discrimination accuracy of $80 \%-85 \%{ }^{(17)}$ Saini et al developed discriminant function equations for ten craniofacial parameters and reported success rates of $61.8 \%-85.5 \%$ in a North Indian population. ${ }^{(4)}$ Our study, which was conducted on a South Indian population, resulted in an accuracy of $58.8 \%-68.8 \%$ for sex prediction, comparable to that of the study conducted on North Indians. ${ }^{(4)}$ Bizygomatic breadth provided the highest accuracy for sex determination in both the North and South Indian studies, in agreement with the reports of other researches in different populations..$^{(4,14-17)}$ Following bizygomatic breadth, Saini et al found orbital breadth to be the second best discriminant in North Indians; ${ }^{(4)}$ in our study on South Indians, however, upper facial height was found to be the second best discriminant of sex. These differences in anthropometric traits between North and South Indians may be due to their different origins. The Indian population is derived from four primary ethnic groups: Caucasoid, Mongoloid, Australoid and Negrito. ${ }^{(22)}$ North Indians, referred to as Aryans, belong to the Caucasian race, whereas South Indians, the original inhabitants of the country, called Dravidians, are classified as members of the Proto-Australoid or Australoid race. Differences in the morphological characteristics of these two races have been reported.(22)

In the present study, sex determination using craniofacial morphometry parameters was established for the South Indian population. Our findings could be of clinical importance, interest to forensic anthropologists and value in genetic studies. The craniofacial parameters derived for sexual dimorphism serves as a framework for future studies comparing the craniofacial anatomy of indigenous racial groups.

\section{ACKNOWLEDGEMENTS}

The authors are grateful to Yenepoya University for permission to carry out this study.

\section{REFERENCES}

1. Rogers TL. Determination of sex of human remains through cranial morphology. J Forensic Sci 2005; 50:493-500.

2. Naccarato $S$, Petersen $S$, John GL. Skull features as clues to age, sex, race and lifestyle. J Forensic Ident 2008; 58:172-81.

3. Bilge Y, Kedici PS, Alakoç, YD, Ülküer KU, İlkyaz YY. The identification of a dismembered human body: a multidisciplinary approach. Forensic Sci Int 2003; 137: 141-6.

4. Saini V, Srivastava R, Rai RK, et al. An Osteometric Study of Northern Indian Populations for Sexual Dimorphism in Craniofacial region. J Forensic Sci 2011; 56:700-5.

5. Franklin D, O'Higgins $P$, Oxnard CE, Dadour I. Discriminant function sexing of the mandible of indigenous South Africans. Forensic Sci Int 2008; 179:84.

6. Gapert R, Black S, Last J. Sex determination from the foramen magnum: discriminant function analysis in an eighteenth and nineteenth century British sample. Int J Legal Med 2009; 123:25-33.

7. Kranioti EF, Iscan MY, Michalodimitrakis M. Craniometric analysis of modern Cretan population. Forensic Sci Int 2008; 180:110.

8. Vodanovic M, Dumancic J, Demo Z, Mihelic D. [Determination of sex by discriminant function analysis of mandibles from two Croatian archeological sites.] Acta Stomatol Croat 2006; 40:263-77. Croatian.

9. Celbis O, Iscan MY, Soysal Z, Cagdir S. Sexual diagnosis of the glabellar region. Legal Med (Tokyo) 2001; 3:162-70.

10. Kemkes A, Gobel T. Metric assessment of the "mastoid triangle" for sex determination: a validation study. J Forensic Sci 2006; 51:985-9.

11. Suazo GIC, Zavando MDA, Smith RL. Sex determination using mastoid process measurements in Brazilian skulls. Int J Morphol 2008; 26:941-4. 
12. Wescott DJ, Moore-Jansen PH. Metric variation in the human occipital bone: forensic anthropological applications. J Forensic Sci 2001; 46:1159-63.

13. Gulekon IN, Turgut HB. The external occipital protuberance: can it be used as a criterion in the determination of sex? J Forensic Sci 2003; 48:513-6.

14. Naikmasur VG, Shrivastava R, Mutalik S. Determination of sex in South Indians and immigrant Tibetans from cephalometric analysis and discriminant functions. Forensic Sci Int 2010; 197:122.e1-6.

15. Oladipo GS, Akande PA, Osogba IG, Yorkum KL. Anthropometric studies of inner canthal distance, outer canthal distance and canthal index of adult Ibibios. Asian J of Med Sci 2011; 3:14-6.

16. Steyn M, Iscan MY. Sexual dimorphism in the crania and mandibles of South African whites. Forensic Sci Int 1998; 98: 9-16.
17. Dayal MR, Spocter MA, Bidmos MA. An assessment of sex using the skull of black South Africans by discriminant function analysis. Homo 2008; 59:209-21.

18. Krishan K. Anthropometry in Forensic Medicine and Forensic Science'Forensic Anthropometry'. Internet J Forensic Sci 2007; 2(1).

19. Farkas LG , Posnick J C, Hreezko TM. Anthropometric growth study of the head. Cleft Palate Craniofac J 1992; 29:303-8.

20. Franklin D, Freedman L, Milne N, Oxnard CE. A geometric morphometric study of sexual dimorphism in the crania of indigenous southern Africans. S. Afr J Sci 2006; 102:229-38.

21. Franklin D, Freedman L, Milne N. Sexual dimorphism and discriminant function sexing in indigenous South Africa crania. Homo 2005; 55:213-28.

22. Malhotra KC. Morphological composition of the people of India. J Hum Evol 1978; 7:45-53

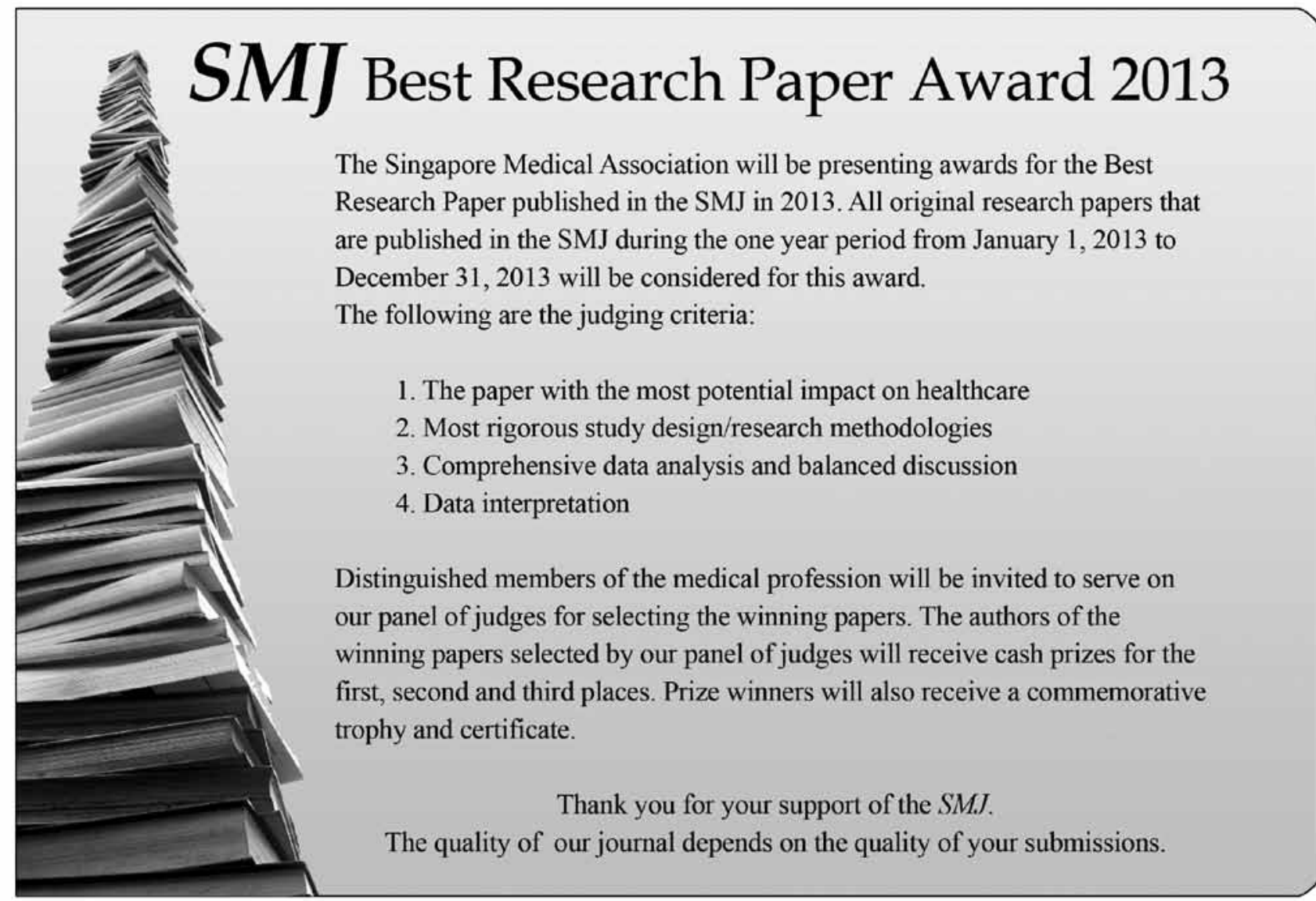

